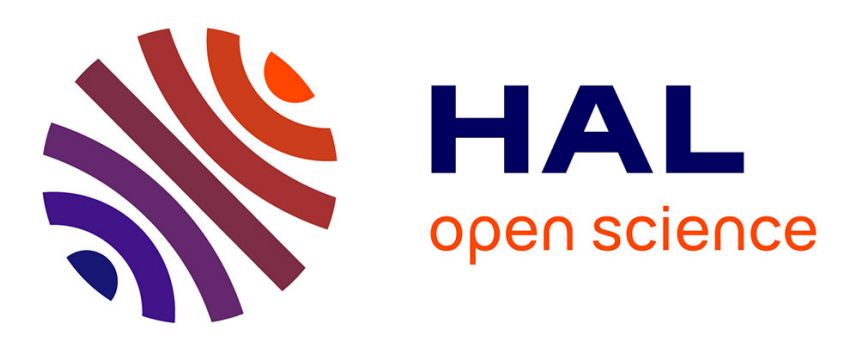

\title{
Delayed Detached Eddy Simulations of Rough-Wall Turbulent Reactive Flows in a Supersonic Combustor
}

Guillaume Pelletier, Marc Ferrier, Axel Vincent-Randonnier, Arnaud Mura

\section{To cite this version:}

Guillaume Pelletier, Marc Ferrier, Axel Vincent-Randonnier, Arnaud Mura. Delayed Detached Eddy Simulations of Rough-Wall Turbulent Reactive Flows in a Supersonic Combustor. 23rd AIAA International Space Planes and Hypersonic Systems and Technologies Conference, Mar 2020, Montreal, Canada. 10.2514/6.2020-2409 . hal-03224513

\section{HAL Id: hal-03224513 \\ https://hal.science/hal-03224513}

Submitted on 9 Jun 2021

HAL is a multi-disciplinary open access archive for the deposit and dissemination of scientific research documents, whether they are published or not. The documents may come from teaching and research institutions in France or abroad, or from public or private research centers.
L'archive ouverte pluridisciplinaire HAL, est destinée au dépôt et à la diffusion de documents scientifiques de niveau recherche, publiés ou non, émanant des établissements d'enseignement et de recherche français ou étrangers, des laboratoires publics ou privés. 


\title{
Delayed Detached Eddy Simulations of Rough-Wall Turbulent Reactive Flows in a Supersonic Combustor
}

\author{
Guillaume Pelletier*, Marc Ferrier ${ }^{\dagger}$ and Axel Vincent-Randonnier ${ }^{\ddagger}$, \\ ONERA Université Paris Saclay, Palaiseau, France, F-91123 \\ Arnaud Mura ${ }^{\S}$ \\ Ecole Nationale Supérieure de Mécanique et d Aérotechnique, Pprime Institute UPR3346 CNRS, Futuroscope, \\ France, 86961
}

\begin{abstract}
Reactive Delayed Detached Eddy Simulations (DDES) of hydrogen injected into a transverse supersonic flow of vitiated air are conducted. The corresponding experimental conditions are studied in the LAPCAT-II combustor operated in the LAERTE facility of ONERA Palaiseau Research Center. Due to thermal coating, the wall surfaces of this combustor exhibit wall roughness, the mean characteristic height of which is $65 \mu \mathrm{m}$. The effects of this wall roughness on the turbulent reactive flow development is taken into account within the sand-grain modeling framework. Computational results are assessed through a comparison with available experimental data that gather direct visualizations, including $\mathbf{O H}^{*}$ and Schlieren imaging, as well as wall pressure measurements. In comparison with smooth-wall computations, the roughwall numerical simulations lead to a significant improvement of the agreement with available experimental data.
\end{abstract}

\section{Introduction}

Non-premixed supersonic combustion has been extensively studied over the last thirty years, and a huge amount of well-documented experimental databases have been documented in the literature [1-5].The LAPCAT-II experiments conducted in the LAERTE facility of ONERA Palaiseau Research Center [6, 7] gather such data within a scramjet-like environment with conditions representative of a Mach 6 supersonic flight.

Computational invistigation of supersonic combustion is challenging for many facets of the corresponding models including the numerical scheme accuracy, the physical models (turbulence, turbulence chemistry interaction) or the wall modeling. The issue of turbulent mixing representation may be addressed through several options. The RANS framework remains rather questionnable since wall-bounded compressible turbulent flows exhibit a strong dependency to some compressible paterns which are intrinsically unsteady, e.g., shock boundary layers interactions (SBLI). A more

\footnotetext{
*PhD student, Energetics Department, Address/guillaume.pelletier@onera.fr

${ }^{\dagger}$ Research Engineer, Energetics Department, Address/marc.ferrier@onera.fr

† Research Engineer, Energetics Department, Address/axel.vincent@onera.fr

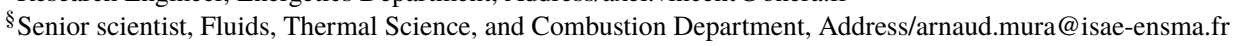


relevant framework, able to give a more satisfactory representation of turbulent mixing may lay in the LES. The detailed computation of the wall dynamics and heat transfer have little effect on the bulk flow in strongly separated flow, and this allows low-resolved LES to be performed at the wall. This is in contrast to flows that display complex interactions between shock-waves and boundary-layer, or when the target is to study wall fluxes, which require the boundary layer to be well represented. Such an objective can be reached with a LES meshing of the boundary layer, this option remains however very expensive for internal aerodynamics such as the one involved in a combustion chamber. In this context, the simulations results achieved by Fureby et al. [8] on the LAPCAT-II geometry are quite noteworthy. It must also be emphasized that the wall roughness effects within the LES framework still ramains challenging [9]. The other possibility, which is retained in the present study, is to meld the LES with a cheaper approach close to the walls. This is the aim of the DDES approach combining RANS modeling of the boundary layer with LES models in the far region.

Furthermore, previous studies of the LAPCAT-II combustor [7, 10] pointed out that wall roughness needs to be taken into account. In these studies, the wall roughness influence on the skin friction was mimicked by and arbitrary increase of the molecular viscosity coefficient while the present work is concerned with a more general methodology, developed within a RANS framework, and based on effective roughness measurements. The objective of the present work is to assess the possibility to use the corresponding RANS roughness model within a DDES framework and to investigate how this model may affect the combustion stabilization and development.

The manuscript is organized as follows: the experimental setup and main test results are presented in section $\Pi$. Then, a brief description of the computational model is provided in section [III The analysis of the computational results in section IV] includes a comparison of the numerical simulation results with the experiment data followed by a detailed investigation of the flow modifications induced by the use of the wall roughness model.

\section{Experimental Set-up}

The LAPCAT-II combustor (see Figure 2) is a constant width combustor composed of four successive sections. The first one, which operates as an isolator, has a constant height of $35.4 \mathrm{~mm}$ and spans over $215 \mathrm{~mm}$. This isolator is followed by three diverging sections characterized by a one-degree (318 mm length), a three degree (354.5 mm length), and a one degree (305 $\mathrm{mm}$ length) diverging half angle preventing the high-speed flow from thermal chocking.

This combustion chamber is fed with a hot vitiated airstream, which is generated by the preliminary combustion of a $\mathrm{H}_{2}$-air mixture followed by $\mathrm{O}_{2}$ replenishment to keep the value of the oxygen molar fraction equal to 0.21 . This combustor is fueled with hydrogen injected through two sonic injectors ( $2 \mathrm{~mm}$ diameter) located at $x=200 \mathrm{~mm}$ in the symmetry plane of the top and bottom walls of the test section. It is equipped with pressure sensors along the walls and features large optical accesses allowing $\mathrm{OH}^{*}$ and schlieren visualizations.

The combustion chamber is made of a copper alloy and its inner walls are coated with a $300 \mu m$ thick Thermal Barrier Coating (TBC) made of Yttria-stabilized Zirconia (Yttria denotes Yttrium oxyde), see Figure1. This TBC 
surface is similar to sandpaper and it has been characterized using Scanning Electron Microscopy (SEM), showing an average characteristic roughness size of around $65 \mu \mathrm{m}$.

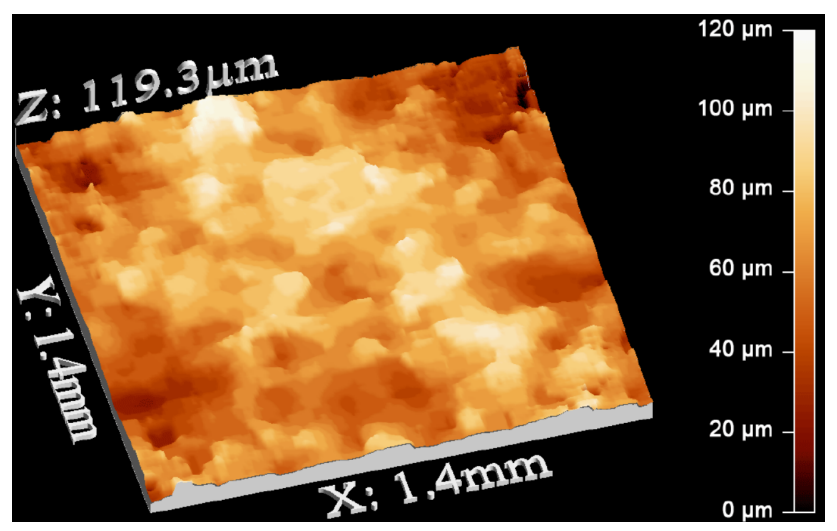

Fig. 1 SEM 3D reconstruction of the LAPCAT-II surface

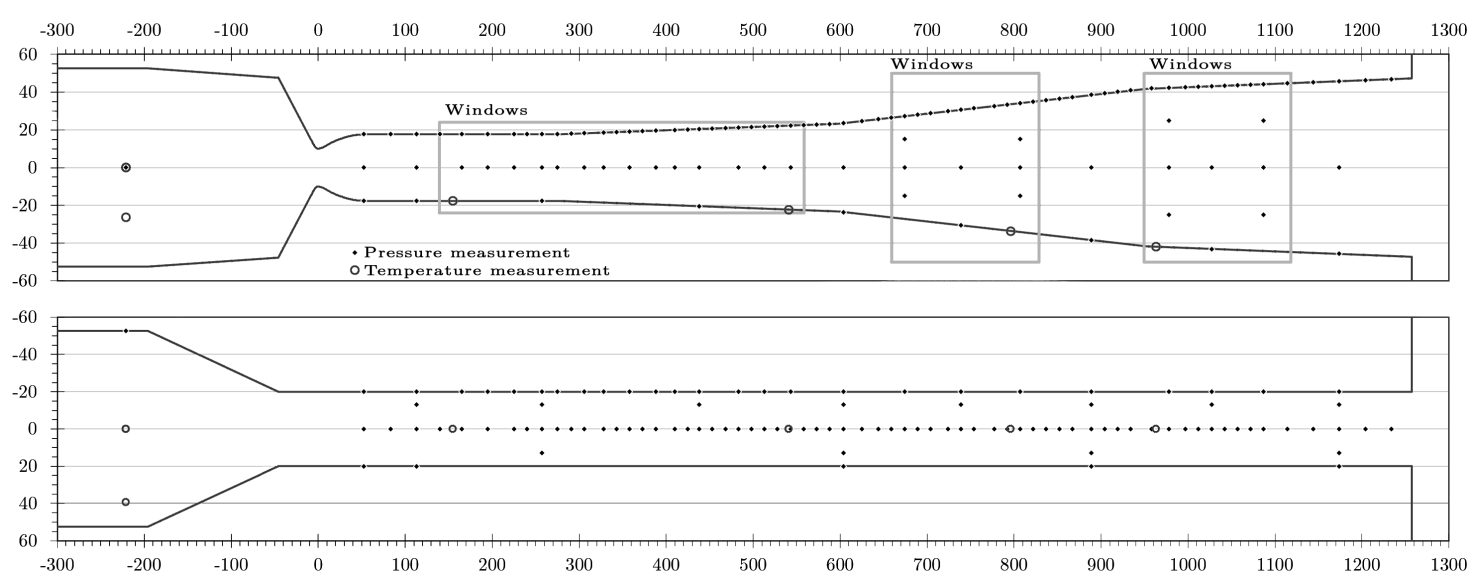

Fig. 2 Geometry of the LAPCAT-II combustor

The present study is focused on the consideration of only one of the different experimental run, which is referenced 20151123-R10. The corresponding conditions are gathered in Table 1.

\section{Table 1 Experimental conditions}

\begin{tabular}{lcccccccc}
$P_{t}(\mathrm{bar})$ & $T_{t}(\mathrm{~K})$ & $Y_{N_{2}}$ & $Y_{\mathrm{O}_{2}}$ & $Y_{\mathrm{H}_{2} \mathrm{O}}$ & $q(g / s)$ & $P_{t, j}(\mathrm{bar})$ & $T_{t, j}(\mathrm{~K})$ & $\Phi$ \\
\hline 4.03 & 1704 & 0.5775 & 0.2554 & 0.1671 & 290.1 & 3.91 & 305 & 0.121
\end{tabular}

Figure 3 displays $\mathrm{OH}^{*}$ chemiluminescence superimposed on Schlieren imaging. It seems worth recalling that the injection is located at $x=200 \mathrm{~mm}$. As emphasized in reference [7], this injection is responsible for the shock reflections that can be observed in grayscale in Figure 3 The $\mathrm{OH}^{*}$ emission, represented in red-scale, shows that the combustion starts far downstream of the $\mathrm{H}_{2}$-injection at abscissas that are larger than $260 \mathrm{~mm}$ for the upper wall and larger than $300 \mathrm{~mm}$ for the lower wall. In these experimental conditions, the upper and lower combustion stabilization zones are 
not established at the same location and moves back and forth on the top and bottom walls. The flow-field does not seem to be dramatically distorted by the combustion development. This indicates that this is a rather standard mode of supersonic combustion where the injected fuel mixes with the vitiated air-stream and, after a certain induction time, thermal runaway takes place leading to $\mathrm{OH}^{*}$ production.

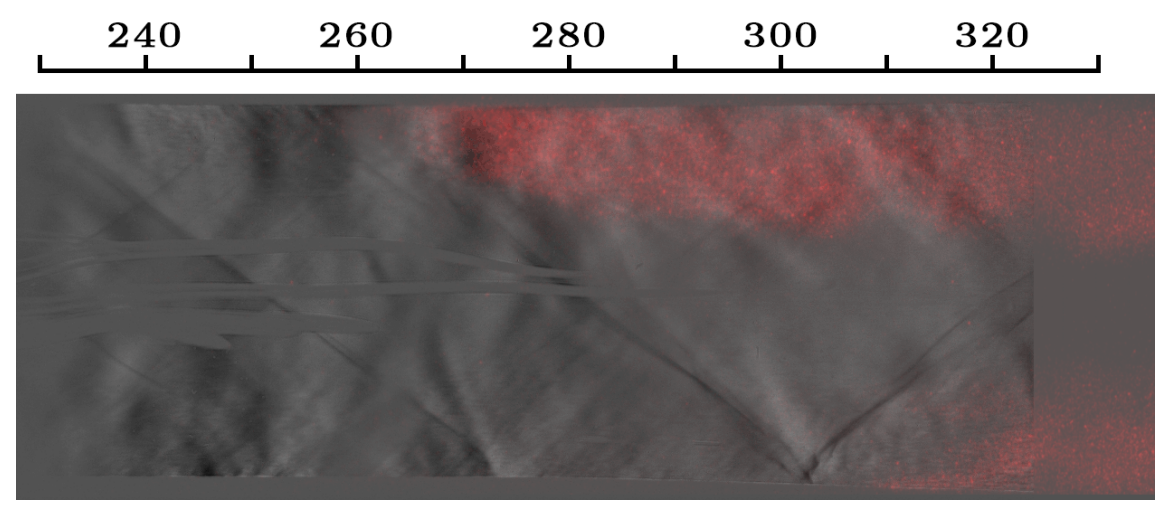

Fig. 3 Strioscopy (gray-scale) and $\mathrm{OH}^{*}$ chemiluminescence (red-scale) as obtained for the 20151123-R10 run

\section{Description of the computational model}

The present study is conducted with the ONERA computational fluid dynamics code CEDRE [11] which is a multi-physics platform relying on specific solvers to handle complex flow simulations. In this study only the finite volume three-dimensional compressible and reactive Navier-Stockes solver CHARME is used.

\section{A. Computational setup}

The computational domain spans from $195 \mathrm{~mm}$ before the throat of the Mach 2 De Laval nozzle up to $650 \mathrm{~mm}$ downstream. This domain covers only the started part of the combustor. In order to reduce the computational cost of the simulations presented in this study only half of the chamber is considered and it should be precised that only the averaged results will be considered in the further analysis. The boundary conditions are precised in Figure 4.

- Green boundaries correspond to inlet conditions. The vitiated air inlet, on the left side of the figure, is specified with stagnation pressure and temperature. The velocity is adjusted so as to enforce the mass flow rates, which are determined from a chocked nozzle condition. The hydrogen injection is modeled as a surface where sonic inlet Dirichlet conditions are applied.

- Blue boundaries correspond to no-slip conditions, the roughness model is applied to these walls.

- Red boundaries represent the symmetry plane.

- Yellow boundaries represent a supersonic outlet where all quantities are determined from extrapolation rules. 


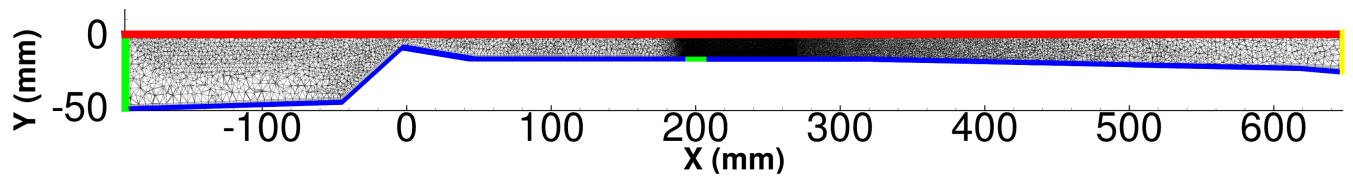

Fig. 4 Computational domain retained to perform the numerical simulation of the LAPCAT-II combustion chamber. Boundary conditions are delineated in color.

\section{B. Computational mesh}

The mesh is composed of prism layers along the walls and tetrahedrons in the rest of the flow. The whole computational mesh features approximately 23.4 millions of cells. The fuel injection and mixing layer regions are refined to obtain a satisfactory description of the mixing layer growth rate. The characteristic cell size in the mixing layer region is computed using a criterion $\Delta=\Delta v_{x} /\left[10 \max \left(\partial v_{x} / \partial y\right)\right]$ which is here expressed considering a $2 \mathrm{D}$ mixing layer. The quantity $\Delta v_{x}$ represents the velocity difference between the two layers and $\partial v_{x} / \partial y$ the velocity gradient along the transverse direction. A first RANS computation is conducted allowing to locate high vorticity zones in the wake of the injection. The computed norm of the vorticity is subsequently used as a threshold to apply the above criterion. Figure 5 gives a view of the mesh in the vicinity of the injection the mixing layer. The profile of the dimensionless height $y^{+}$obtained in the plane $\mathrm{Z}=0$ for the computational cells at the wall location shows that, in the region of interest, the values of $y^{+}$remains smaller than unity.

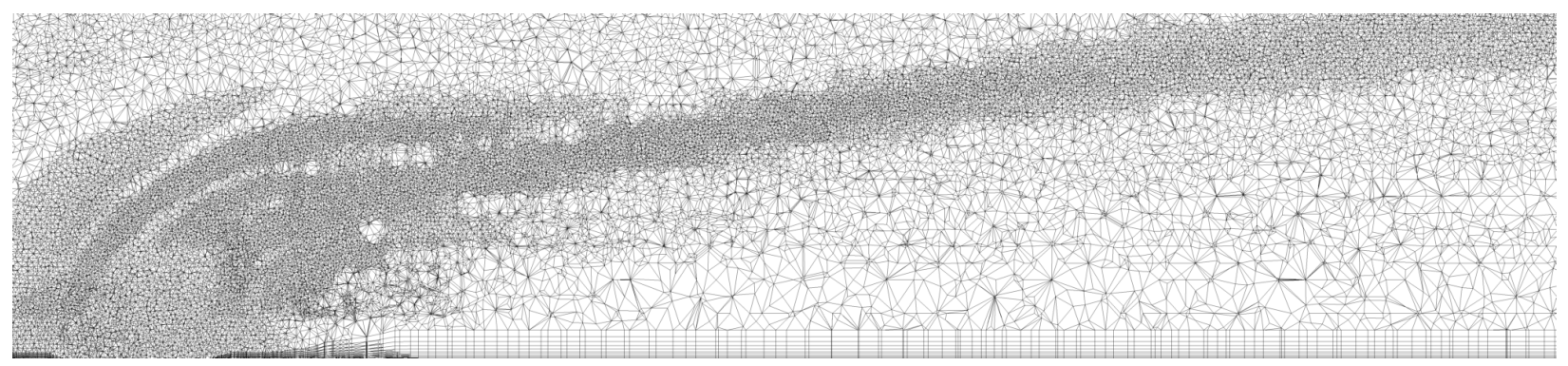

Fig. 5 Mesh in the vicinity of the injector and mixing layer

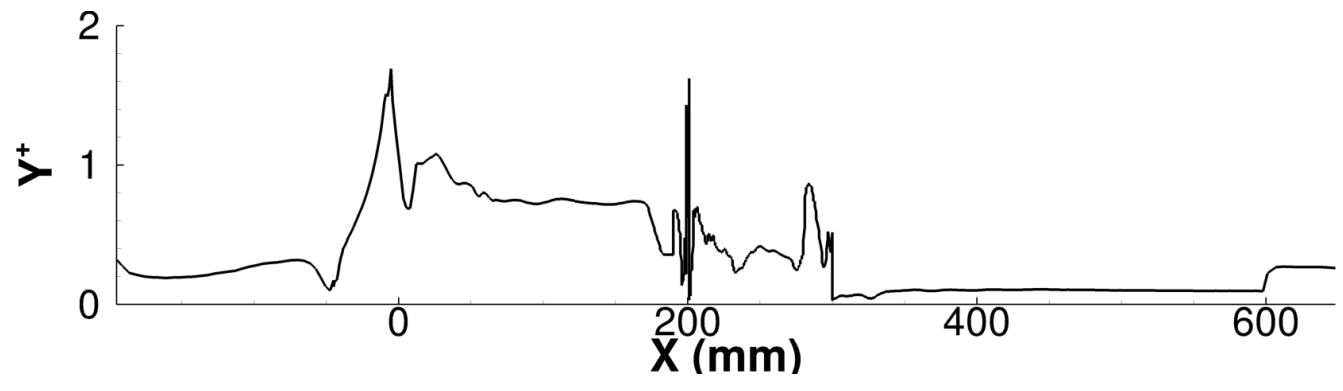

Fig. 6 Profile of $y^{+}$in the symmetry plane

The computational results are mirrored with respect to the symmetry plane, in order make easier the comparison with experimental visualizations. 


\section{Physical modeling}

\section{Delayed Detached Eddy Simulation}

As suggested by Strelets [12], the DDES model used in this study results from a modification of the original DDES model [13], which was developed within the Spalart Almaras modelling framework[14], in order to use it in conjunction with the two equations k- $\omega$ SST model [15]. The main idea of the present DDES model is to modify the dissipation term of the transport equation for the turbulent kinetic energy $k$, that is $D_{R A N S}^{k}=\rho k^{3 / 2} / l_{R A N S}$, by replacing the integral length $l_{R A N S}$ by a characteristic dimension of the computational cell size $l_{D D E S}$. This modification leads to a Smagorinsky like subgrid scale (sgs) viscosity in regions where there is an equilibrium between turbulent kinetic energy production and dissipation. The length scale is provided in Eq.(1). It includes a DDES factor that prevents early transition to LES by protecting the RANS boundary layer (Model Stress Depletion [13]). Its expression is given by Eq2

$$
\begin{gathered}
l_{D D E S}=l_{R A N S}-f_{D D E S} \times \max \left(0, l_{R A N S}-C_{D E S} \Delta\right) \\
f_{D D E S}=1-\tanh \left(\frac{1}{\omega} \max \left(\frac{500 v}{d_{\omega}}, \frac{\sqrt{k}}{\beta^{*} d_{\omega}}\right)\right)
\end{gathered}
$$

As most of the constant involved in the Menter's k- $\omega$ SST model, the value of $C_{D E S}$ is blended using the $F_{1}$ transition function, which is equal to unity in the near wall region and going to zero far from the walls:

$$
C_{D E S}=\left(1-F_{1}\right) C_{D E S}^{k-\epsilon}+F_{1} C_{D E S}^{k-\omega}
$$

Both constants $C_{D E S}^{k-\epsilon}$ and $C_{D E S}^{k-\omega}$ have been calibrated 0.61 and 0.78 , respectively.

\section{Roughness Model}

The equivalent sand grain approach is retained in the present study to take wall roughness into account. The objective of this methodology is to reproduce the skin friction increase induced by wall roughness. This skin friction increase can be related to a downward shift of the velocity profile within the logarithmic region of the boundary layer [16]. Correlations evaluating this velocity shift as a function of a quantity suited to represent the roughness, i.e., the equivalent sand grain height $k_{s}$, have been proposed [17-19]. Within the RANS framework, a common solution consists in modifying the wall boundary conditions of the turbulence models so as to reproduce the skin friction increase, or equivalently, the velocity shift [20-24]. In the present study, the methodology developped by Aupoix et al. [20] is retained.

In the direct vicinity of the wall, a region, called the roughness sublayer, is highly perturbed by the protusions present at the walls. In this region, the main flow characteristics, once scaled by the increased friction level, are expected 
to retain some similarities with those developing over smooth surfaces, meaning that the logarithmic law is preserved but shifted. The velocity shift approach thus consists in deducing the velocity derivative in rough wall conditions from a velocity shift applied to the normalized velocity profile associated to smooth wall conditions. This may be illustrated by considering two distinct frames of reference with one related to the rough wall flowfield and the other related to the smooth wall flowfield. The corresponding longitudinal components of the velocity are denoted $u_{r}^{+}$and $u_{s}^{+}$for the rough and smooth walls, respectively, and the principle of the method is schematically depicted in Figure 7 The superscript + denotes variables that are scaled by the friction velocity $u_{\tau}=\tau_{w} / \rho$ where $\tau_{w}$ denotes the friction at the wall and $\rho$ is the density.

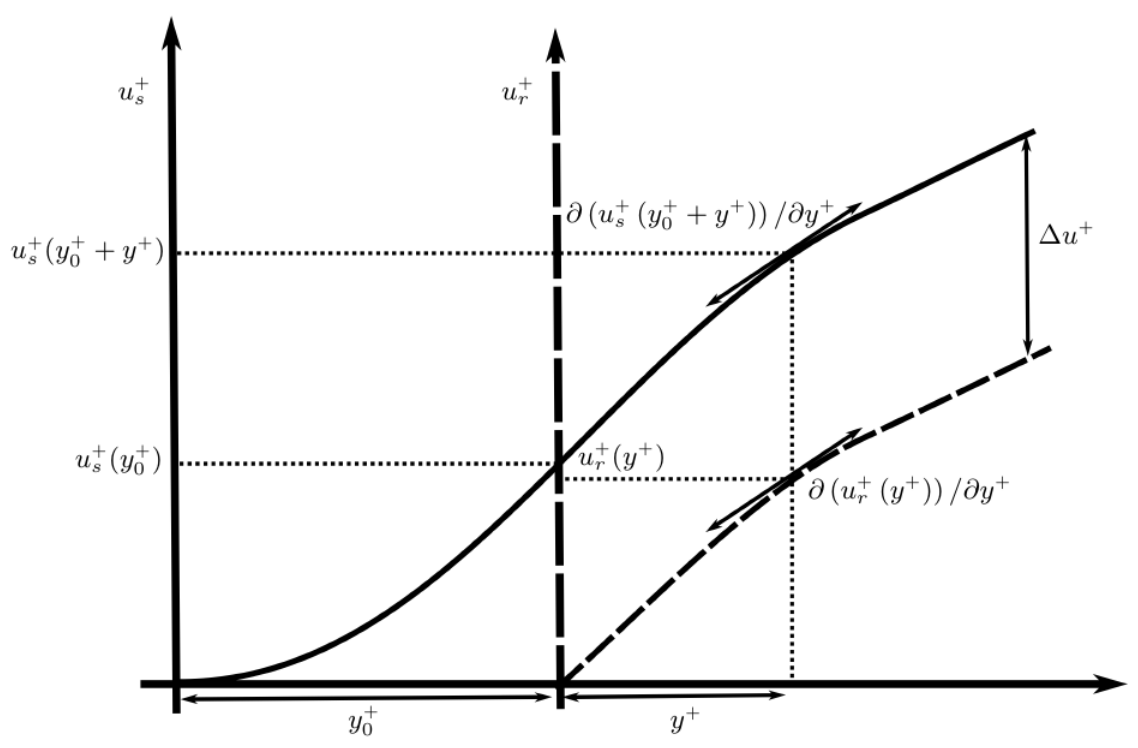

Fig. 7 Illustration of the velocity shift procedure

From a practical viewpoint, the velocity shift is determined from the velocity profile obtained along a smooth wall with the condition that it corresponds to the same flow resistance, i.e., the same velocity gradient, as the one obtained along the rough wall:

$$
\frac{\partial}{\partial y^{+}}\left(u_{r}^{+}\left(y^{+}\right)\right)=\frac{\partial}{\partial y^{+}}\left(u_{s}^{+}\left(y^{+}+y_{0}^{+}\right)\right)
$$

where $y_{0}^{+}$denotes the shift that is applied when changing from the rough-wall towards the smooth-wall frame of reference. Once integrated, this leads to $u_{r}^{+}\left(y^{+}\right)=u_{s}^{+}\left(y^{+}+y_{0}^{+}\right)-u_{s}^{+}\left(y_{0}^{+}\right)$, thus leading to an expression of the velocity shift $\Delta u^{+}=u_{s}^{+}\left(y^{+}+y_{0}^{+}\right)-u_{r}^{+}\left(y^{+}\right)=u_{s}^{+}\left(y_{0}^{+}\right)$which shows that it is equal to the velocity obtained at a distance $y_{0}^{+}$from a smooth wall. In this respect, it is noteworthy that the dimensionless momentum equation in the near wall region reads $\left(1+v_{t}^{+}\right)\left(\partial u^{+} / \partial y^{+}\right)=1$, thus implying that the shift of coordinates applies to the turbulent viscosity [20]. It also applies to the normalized turbulent kinetic energy and frequency, in such a manner that one may write $k_{r}^{+}\left(y^{+}\right)=k_{s}^{+}\left(y^{+}+y_{0}^{+}\right)$ and $\omega_{r}^{+}\left(y^{+}\right)=\omega_{s}^{+}\left(y^{+}+y_{0}^{+}\right)$. Models providing the normilized ordinate $y_{0}^{+}$at which the velocity magnitude on smooth 
wall is equal to the velocity shift $\Delta u^{+}$can be determined for reference solutions and can be established for each specific turbulence closure. Finally, for rough-wall conditions, finite values are imposed at the wall for the turbulent kinetic energy and specific dissipation, and, for the SST model, which is presently retained as the turbulence closure, the corresponding expressions for $k_{r}^{+}\left(y^{+}=0\right)=k_{s}^{+}\left(y_{0}^{+}\right)$and $\omega_{r}^{+}\left(y^{+}=0\right)=\omega_{s}^{+}\left(y_{0}^{+}\right)$can be found in reference [20].

\section{Chemical production rates}

The averaged chemical production rates $\overline{\dot{\omega}}_{\alpha}$ that appear in the species mass fraction transport equations are modeled within the Well-Stirred Reactor (WSR) or quasi-laminar framework, which neglects the possible influence of unresolved fluctuations of composition at the resolved level, i.e, $\bar{\omega}_{\alpha}=\dot{\omega}_{\alpha}\left(\widetilde{T}, \widetilde{Y}_{\alpha}\right)$. It is recalled that, in the present study, combustion is expected to be chemistry-controlled. The corresponding reactions rates are evaluated from the detailed chemical scheme of Jachimowski [25].

\section{Numerical Schemes}

The numerical treatment of inviscid fluxes makes use of the HLLC (Harten-Lax-van Leer Contact) approximate Riemann solver [26]. Second-order accuracy is achieved via variable extrapolation monotonic using upwind scheme for conservation laws (MUSCL) applied in conjuction with Van Leer flux limiters to ensure monotonicity [27, 28]. The viscous fluxes are evaluated with a second-order centered scheme.

\section{E. Statistical convergence of the computational datasets}

Before embarking on the analysis of computational results, a statistical convergence study is conducted. The statisical convergence is assessed via the convergence of the second-order moments residuals [29] of the pressure, velocity, and heat release rate. The second-order moment of any quantity $\Phi$ is analyzed through the squared deviation from its mean value $\sigma_{\Phi}=\left\langle(\langle\Phi\rangle-\Phi)^{2}\right\rangle=\left\langle\Phi^{2}\right\rangle-\langle\Phi\rangle^{2}$ and the convergence is assessed through the computation of the residual of this quantity:

$$
R_{\Phi}=\langle\Phi \Phi\rangle-\langle\Phi\rangle\langle\Phi\rangle-\left\langle(\Phi-\langle\Phi\rangle)^{2}\right\rangle
$$

Nine probes have been placed in the combustion chamber at different locations of the flow, see Figure 8

- the inlet crossflow $\left(P_{1}, P_{2}\right)$,

- the bow shock and downstream reciruclation zone $\left(P_{3}, P_{4}\right)$,

- the shear layer $\left(P_{5}, P_{6}\right)$,

- the combustion zone $\left(P_{7}, P_{8}, P_{9}\right)$.

Figure 9 reports the statistical convergence for both rough and smooth walls simulations. It can be observed that the solution convergence is reached for $t^{*}>100$. The instantaneous data sets that are used for the comparison 


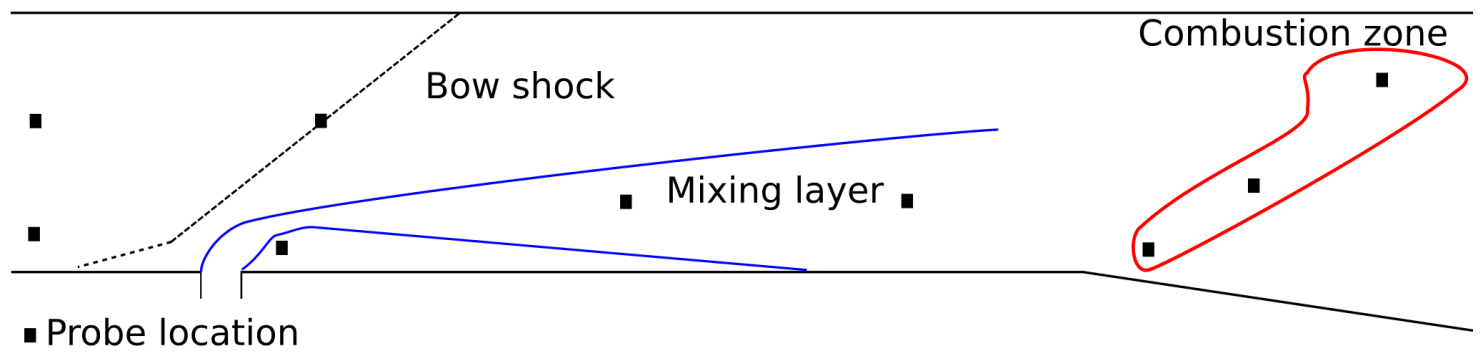

Fig. 8 Sketch of the probe location in the flow

with experiments and further analyses span from $t^{*}=150$ up to the end of the simulation. This corresponds to 10 characteristic residence times in the computational domain.

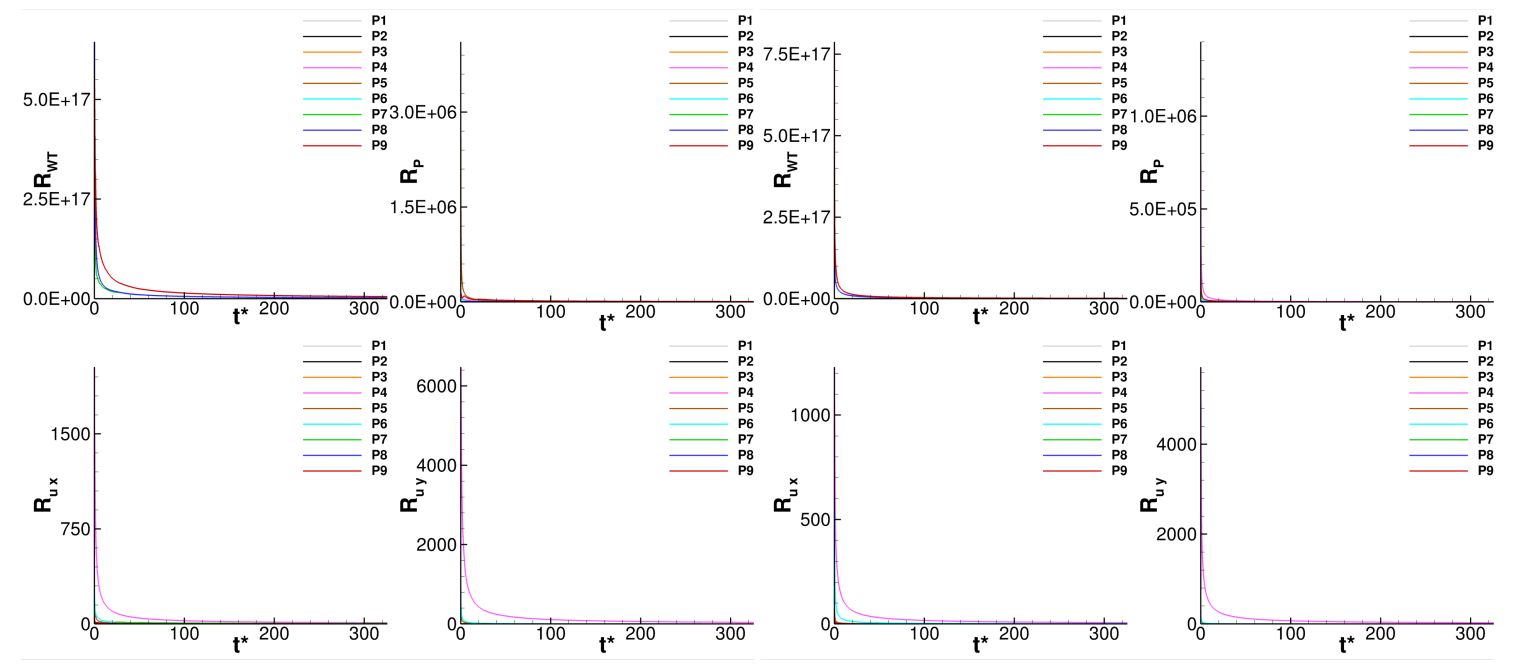

Fig. 9 Statistical convergence of the rough (left) and smooth (right) simulations

\section{Numerical results}

In this section both rough and smooth walls simulations are compared to experiments before performing an analysis of the effects of roughness over combustion stabilization and development.

\section{A. Comparison to experiment}

The comparison is performed on the basis of the computed pressure profile along the wall in the plane of symmetry, see Figure 10 , and the computed field of the heat release rate superimposed on the density gradient, see Figure 11

In both rough and smooth walls simulations, the main flow characteristics remain similar. This flow features the injection at $x=200 \mathrm{~mm}$ inducing the formation of a bow shock which reflects on the walls at abscissas around $x=$ $240 \mathrm{~mm}$ and $x=280 \mathrm{~mm}$. Those reflections are delineated through two pressure peaks, see Figure 10. As it can be deducted from Figure 11 the combustion starts downstream of these reflections in the direct vicinity of the wall to and 
further extends to the core flow. As shown in Figure 10, this heat release induces an increase of the pressure level up to a maximum observed between $x=300 \mathrm{~mm}$ and $x=400 \mathrm{~mm}$. The downstream pressure profile exhibits a constant decreasing slope whereas experimental data display a pressure plateau for abscissas between $x=400 \mathrm{~mm}$ and $x=600$ $\mathrm{mm}$. This difference may lie in (i) the roughness model which has been developed without any special consideration of possible adverse pressure gradients, which may be unsuited for this specific configuration featuring significant flow acceleration, (ii) possible local flow separation that is not computed in the present case because the computational domain is truncated. The pressure drop observed at $x=600 \mathrm{~mm}$ is induced by the divergence angle of the geometry.

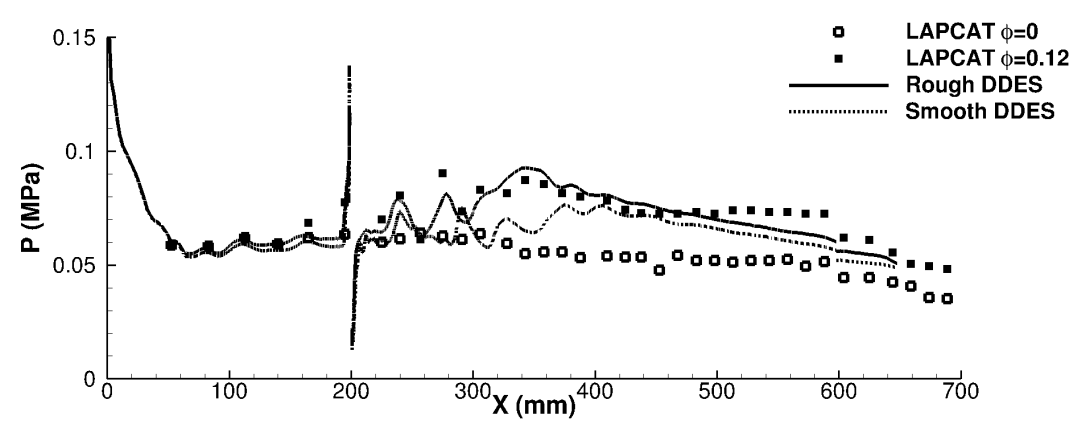

Fig. 10 Wall pressure profiles comparison in the plane of symmetry

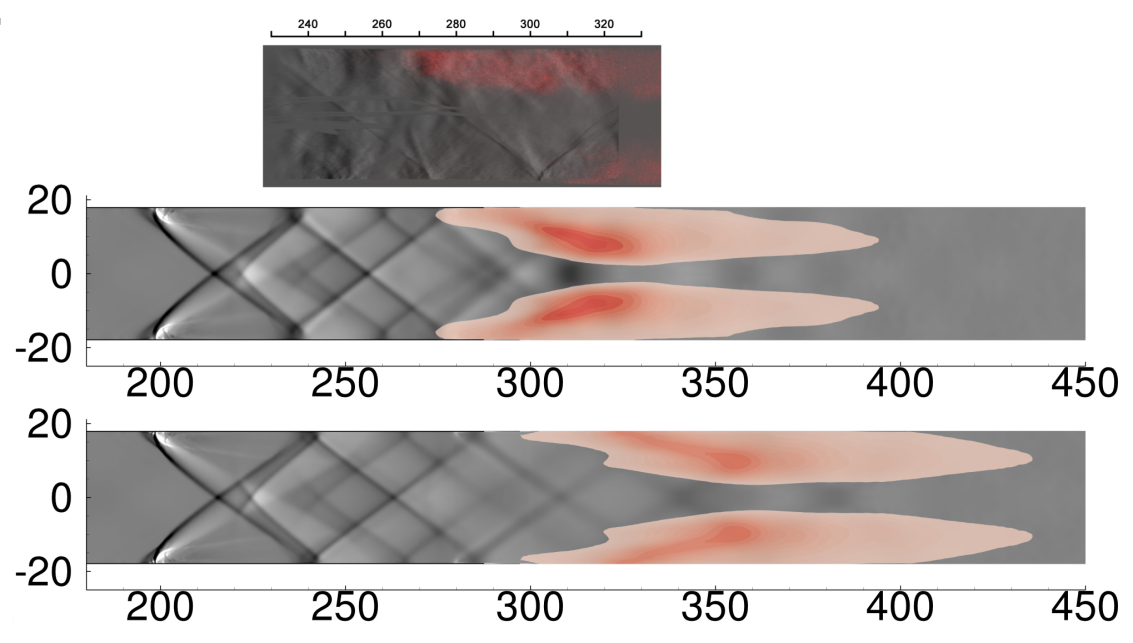

Fig. 11 Wall pressure profiles comparison in the plane of symmetry

The analysis of the pressure profile reported in Figure 10 shows a better level of agreement with respect to experimental data when wall roughness is taken into account. In the non-reactive region, the global pressure level is slightly increased, as the boundary layer is thickened due to the roughness. This thickening also modifies the bow shock reflection which occurs at smaller abscissas. Combustion ignites and stabilizes at this bow shock reflection as it features low velocities and higher temperature levels. Considering the small equivalence ratio $(\Phi=0.12)$, combustion can be considered complete in both cases. Thus, as the combustion spans over a shorter distance in presence of rough walls, 
the pressure levels increase faster than in the smooth case.

\section{B. Effect of roughness on combustion development}

A direct effect of including roughness in the simulation is a thickening of the boundary layer, see Figure 12. Here, the boundary layer thickness is evaluated by $\delta_{90}$ meaning the height is measured when the velocity reach $90 \%$ of its maximum at this location.

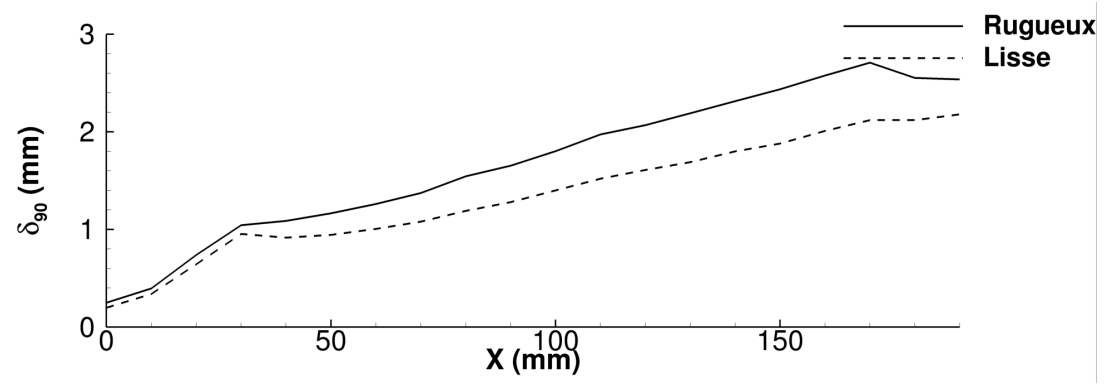

Fig. 12 Boundary layer thickness before injection in the plane of symmetry

This figure shows that the boundary layer is $17 \%$ thicker with roughness, which can have several effects on the flow:

- The boundary layer thickening induces a mean temperature rise and a mean velocity decrease, which can be seen in Figure 13, due to the apparent reduced cross-section and the drag increase.

- As the flow impinges the injection is slower, thus the jet to crossflow momentum ratio $J=\rho_{j} u_{j} / \rho_{\infty} u_{\infty}$ is higher, the fuel can penetrate deeper in the combustion chamber. In present simulations the maximum height reached by two iso-surface $Y_{H 2}=0.1$ and $Y_{H 2}=0.01$ are $12 \%$ higher when roughness is taken into account.

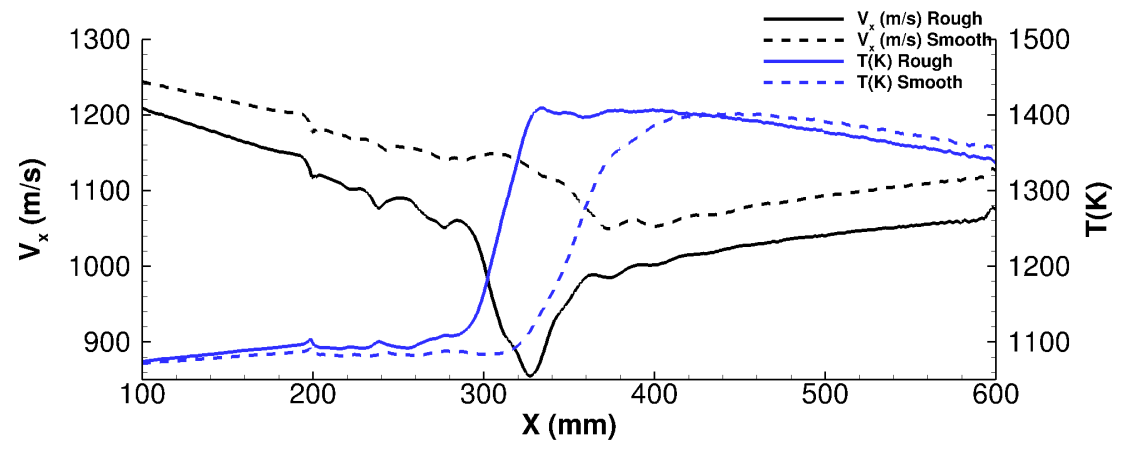

Fig. 13 Mean longitudinal velocity component and temperature profiles

In Figure 13, the value of each parameters are averaged over the whole cross-section. The effect observed on the temperature is comparatively small, $10 \mathrm{~K}$ accounting for $1 \%$ before injection, when compared to the velocity decrease, $60 \mathrm{~m} / \mathrm{s}$ representing $5 \%$ before injection. Considering auto-ignition as the leading order combustion process, the shifted position of the reaction zone, closer to the injection when roughness is considered, can be explained by the lower velocity, increasing the residence time, and higher temperature, reducing the auto-ignition delay. This effect is enhanced 
when considering the fact that combustion starts in the boundary layer. When averaging the velocity over the thickness of the boundary layer, the average speed is reduced by $13 \%$ before the injection.

In the following, five equally spaced slices ( $x=240 \mathrm{~mm}, x=260 \mathrm{~mm}, x=280 \mathrm{~mm}, x=300 \mathrm{~mm}, x=320 \mathrm{~mm}$ ), are used to highlight the possible modifications that may be induced by the roughness on the mixing layer development.

As it can be observed on both field that are represented in Figure 14 for the rough case, combustion starts between $280 \mathrm{~mm}$ and $300 \mathrm{~mm}$, it is associated to a sharp temperature rise and $Y_{H 2}$ consumption. For the smooth case ignition takes place in the $320 \mathrm{~mm}$ slice. For transverse planes located before combustion $(x=240 \mathrm{~mm}, x=260 \mathrm{~mm}, x=280$ $\mathrm{mm}$ ), higher temperature levels are obtained in the vicinity of the mixing layer when wall roughness is considered.

In the planes located at $x=260$ and $x=280 \mathrm{~mm}$, the mean temperature is slightly increased and the maximum $\mathrm{H}_{2}$ mass fraction is decreased when wall roughness is considered. This suggests that, when roughness is considered, the injected fuel spreads over a wider surface. Here, the area delineated by $Y_{H_{2}}>0.001$ (representing one percent of the mass fraction maximum in the $280 \mathrm{~mm}$ section) is greater and is more preheated as the average temperature in this surface is almost ten percent, hotter than in the smooth case.

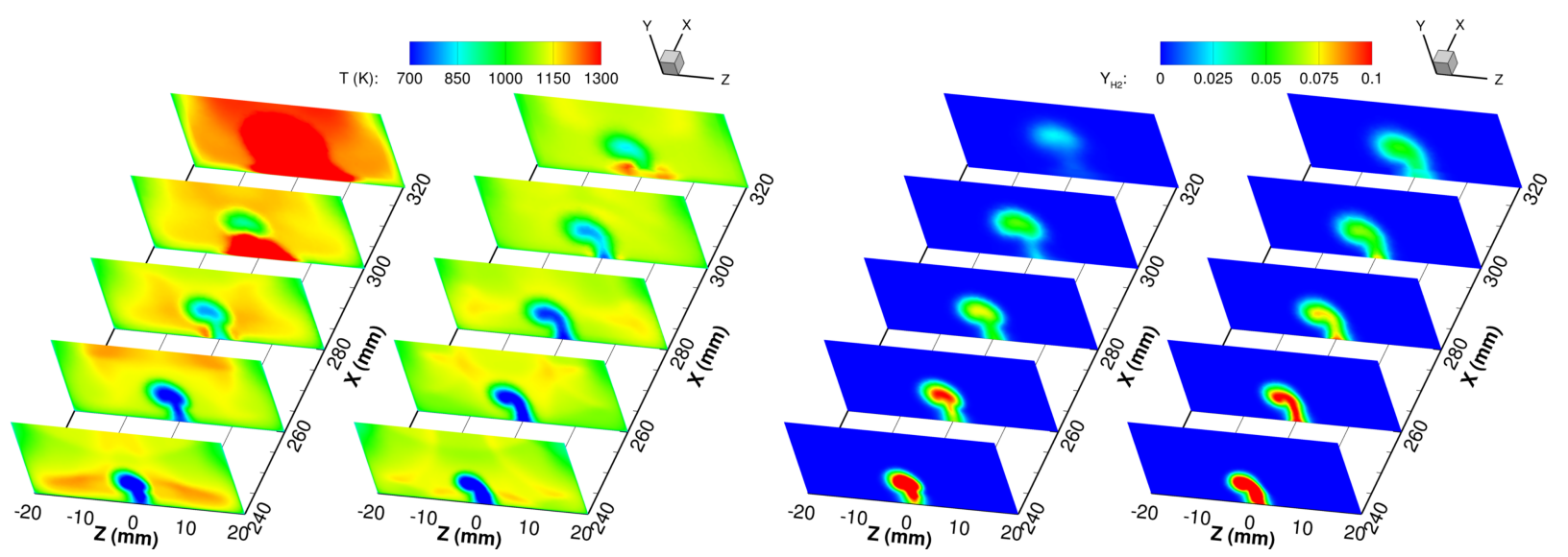

Fig. 14 Temperature and $\mathbf{H}_{2}$ mass fraction contour for the rough (left) and smooth (right) cases

The observed behaviour indicates a stronger mixing of the hydrogen jet with air, which must be related to the turbulent mixing. Turbulent mixing takes place at two different scales: the subgrid-scale level and the resolved scale level. The subgrid-scale turbulent diffusivity is higher in the boundary layer, which is a direct outcome of the roughness model, though no modification appears in the mixing layer.

A resolved equivalent turbulent viscosity may be reconstructed using the Boussinesq assumption.

$$
\overline{\rho u_{i} u_{j}}-\bar{\rho} \widetilde{u_{i}} \widetilde{u_{j}}=\bar{\rho} v_{t}^{e q}\left(\frac{\partial \widetilde{u_{i}}}{\partial x_{j}}+\frac{\partial \widetilde{u_{j}}}{\partial x_{i}}-\frac{2 \delta_{i j}}{3} \frac{\partial \widetilde{u_{k}}}{\partial x_{k}}\right)-\frac{2}{3} \delta_{i j} \bar{\rho} \widetilde{k}
$$

The contributions of $v_{t, x y}^{e q}$ and $v_{t, x z}^{e q}$ are displayed in Figure 16, where $v_{t, x y}^{e q}$ relates to the $x y$ component of the Reynolds stress tensor and $v_{t, x z}^{e q}$, to its $x z$ component. To be able to quantify a difference between the two cases (with 


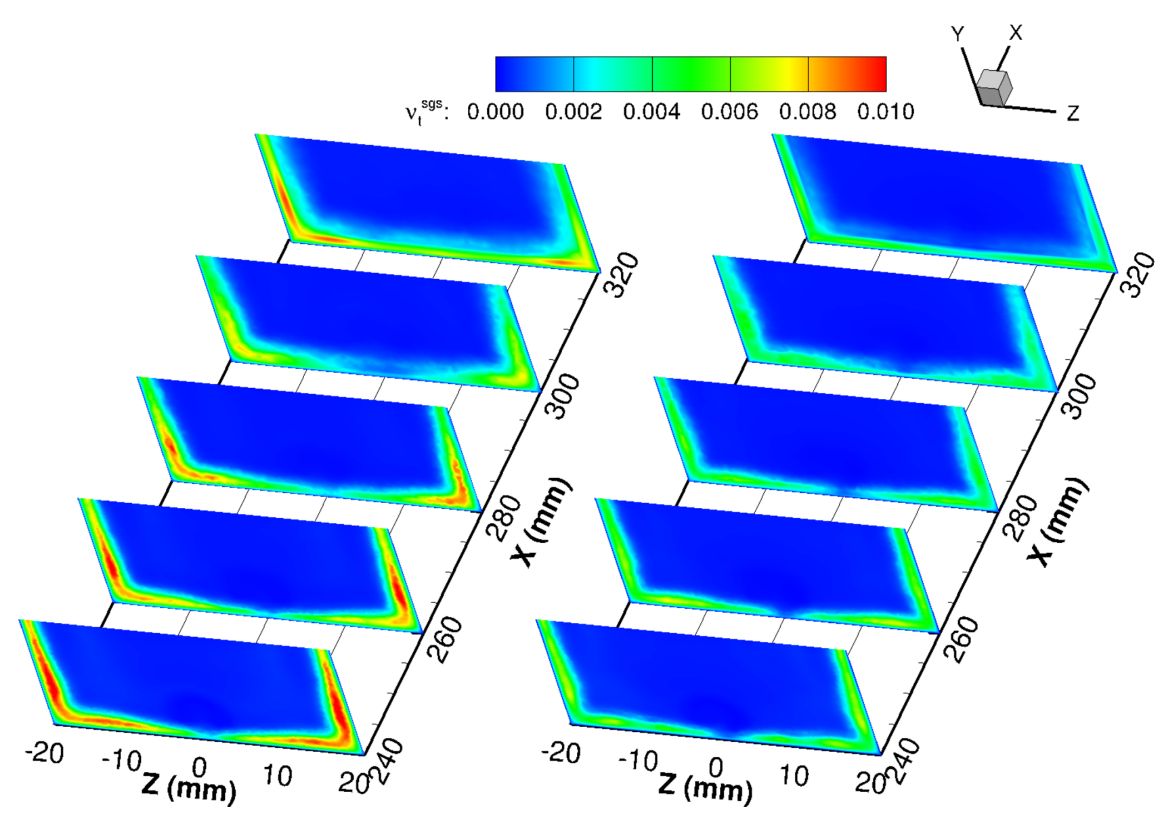

Fig. 15 Subgrid scale turbulent diffusivity

or without roughness), the values of both parameters have been averaged over slices between the injection and the ignition zone, see Figure 17. This figure shows a tenuous increase of the equivalent viscosity for both parameters. The averaged increase of the $x y$ and $x z$ components of $v_{t}^{e q}$ are $21 \%$ and $33 \%$ respectively. It shows that this effect cannot be neglected a priori. This increase of the equivalent turbulent viscosity is difficult to explain within the framework of DES simulations since they assume some separation between the resolved LES and unresolved RANS scales in the boundary layer, where the roughness acts. One explanation could be that, in the rough case, the hydrogen jet penetration in the core flow is stronger, thus producing then stronger shear layers.
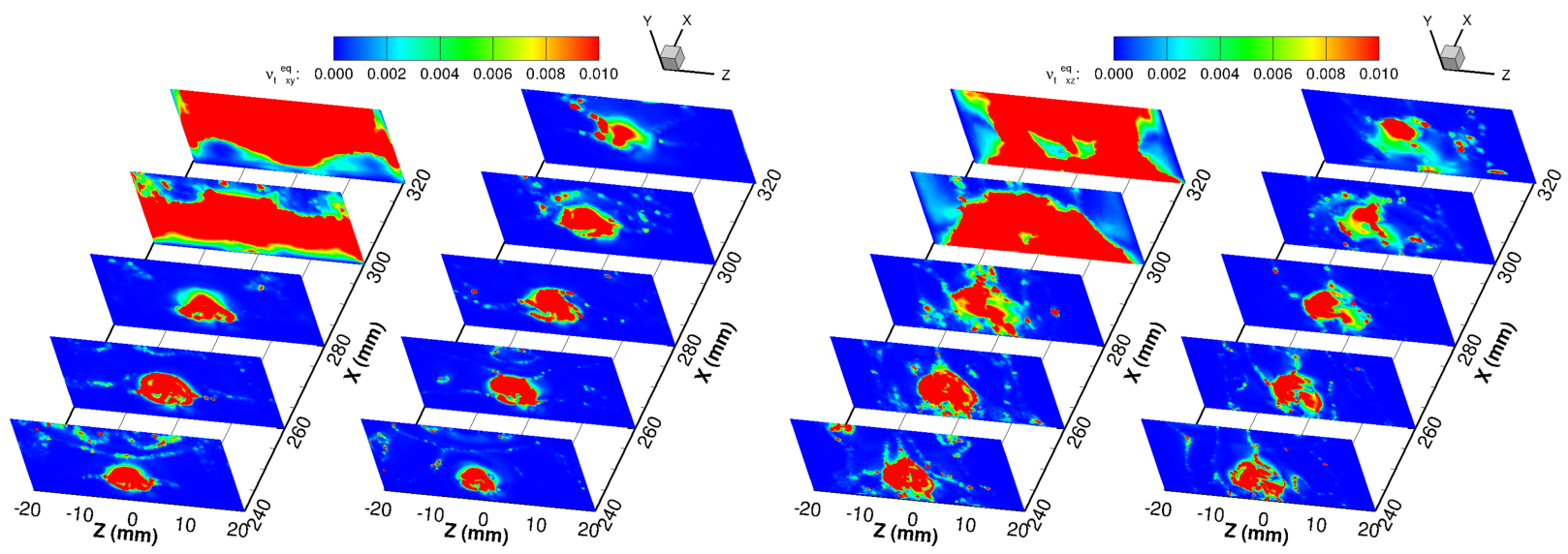

Fig. 16 Resolved scale turbulent diffusivity 

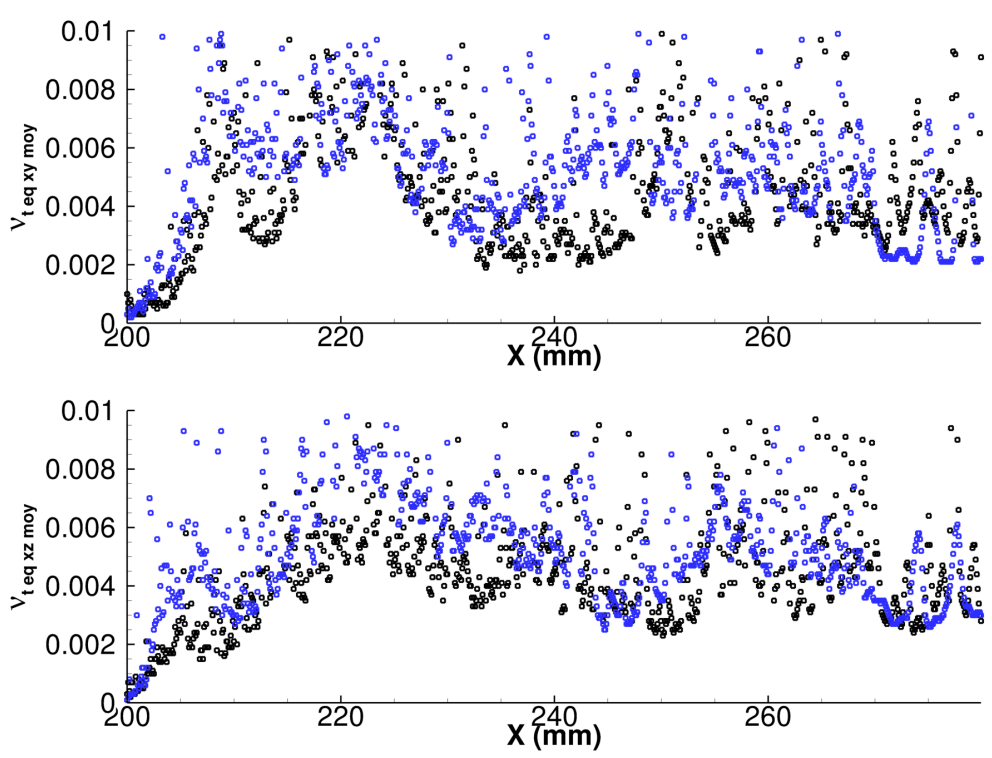

Fig. 17 Averaged resolved scale turbulent diffusivity for the rough (blue) and smooth cases (black)

\section{Conclusions}

The present study has been focused on the DDES simulations of the LAPCAT-II dual mode ramjet/scramjet combustor. The non-negligible wall roughness induced by the thermal barrier coating deposited on the metallic surface of the combustor is considered. The experimental data correspond to supersonic combustion with self-ignition processes following an induction distance. According to the literature the increase in wall friction is associated with a shift in the near-wall velocity profile. In the present set of simulations, the roughness effect is taken into account using an equivalent sand grain approach. The simulations results are assessed on the basis of wall pressure profiles measurements and vizualisations, Schlieren and $\mathrm{OH}^{*}$ chemiluminescence. The numerical simulations results display an improved level of agreement with experimental data when roughness is taken into account. The analysis of the computational results suggests that the influence of the roughness may be related to a (i) lower mean velocity and higher mean temperature of the flow induced by thicker boundary layers and (ii) increase of turbulent transport of momentum and chemical species.

\section{References}

[1] Cheng, T. S., Wehrmeyer, J. A., Pitz, R. W., Jarrett, O., and Northam, G. B., "Raman measurement of mixing and finite-rate chemistry in a supersonic hydrogen-air diffusion flame," Combustion and Flame, Vol. 99, No. 1, 1994, pp. 157 - 173. doi:10.1016/0010-2180(94)90087-6.

[2] Waidmann, W., Alff, F., Bohm, M., Brummund, U., Clauss, M., and Oschwald, M., "Supersonic combustion of hydrogen/air in a scramjet combustion chamber," Space Technology, Vol. 15, No. 6, 1995, pp. 421-429.

[3] Waidmann, W., Brummund, U., and Nuding, J., "Experimental investigation of supersonic ramjet combustion (scramjet)," Transport Phenomena in Combustion, Vol. 2, 1996, pp. 1473-1484. 
[4] Cutler, A., Danehy, P. M., Springer, R. R., and DeLoach, D. P., "CARS thermometry in a supersonic combustor for CFD code validation," AIAA Paper 2002-0743, 2002. doi:10.2514/6.2002-743.

[5] Smart, M. K., Hass, N. E., and Paull, A., "Flight data analysis of the HyShot 2 scramjet flight experiment," AIAA Journal, Vol. 44, No. 10, 2006, pp. 2366-2375. doi:10.2514/1.20661.

[6] Steelant, J., Varvill, R., Walton, C., Defoort, S., Hannemann, K., and Marini, M., “Achievements Obtained for Sustained Hypersonic Flight within the LAPCAT-II project,” AIAA Paper 2015-3677, 2015. doi:10.2514/6.2015-3677.

[7] Vincent-Randonnier, A., Moule, Y., and Ferrier, M., "Combustion of hydrogen in hot air flows within LAPCAT-II dual mode ramjet combustor at Onera-LAERTE facility - experimental and numerical investigation,” AIAA Paper 2014-2932, 2014. doi:10.2514/6.2014-2932.

[8] Vincent-Randonnier, A., Sabelnikov, V., Ristori, A., Zettervall, N., and Fureby, C., "An experimental and computational study of hydrogen-air combustion in the LAPCAT II supersonic combustor,' Proceedings of the Combustion Institute, Vol. 37, No. 3, 2019, pp. 3703-3711. doi:10.1016/j.proci.2018.05.127.

[9] Yang, X. I. A., and Meneveau, C., "Large eddy simulations and parameterisation of roughness element orientation and flow direction effects in rough wall boundary layers," Journal of Turbulence, Vol. 17, No. 11, 2016, pp. 1072-1085. doi:10.1080/14685248.2016.1215604.

[10] Balland, S., and Vincent-Randonnier, A., "Numerical study of hydrogen/air combustion with CEDRE code on LAERTE dual mode ramjet combustion experiment," AIAA Paper 2015-3629, 2015. doi:10.2514/6.2015-3629.

[11] Refloch, A., Courbet, B., , A., Murrone, Villedieu, P., Laurent, C., Gilbank, P., Troyes, J., Tessé, L., Chaineray, G., Dargaud, J.-B., Quémerais, E., and Vuillot, F., “CEDRE Software,” AerospaceLab Journal, 2011, pp. 1-10.

[12] Strelets, M., Detached eddy simulation of massively separated flows, 2001. doi:10.2514/6.2001-879.

[13] Spalart, P. R., Deck, S., Shur, M. L., Squires, K. D., Strelets, M. K., and Travin, A., “A New Version of Detached-eddy Simulation, Resistant to Ambiguous Grid Densities," Theoretical and Computational Fluid Dynamics, Vol. 20, No. 3, 2006, pp. 181-195. doi:10.1007/s00162-006-0015-0.

[14] Spalart, P., and Allmaras, S., “A One-Equation Turbulence Model for Aerodynamic Flows,” AIAA, Vol. 439, 1992. doi: $10.2514 / 6.1992-439$.

[15] Menter, F., “Two-equation eddy-viscosity transport turbulence model for engineering applications," AIAA Journal, Vol. 32, No. 8, 1994, pp. 1598-1605. doi:10.2514/3.12149.

[16] Nikuradse, J., "Law of flows in rough pipes," NACA TM 1292, 1937.

[17] Nikuradse, J., "Strömungsgesetze in rauhen Rohren," Forschg. Arb. Ing.-Wes, Vol. 361, 1933. 
[18] Ligrani, P. M., and Moffat, R. J., "Structure of transitionally rough and fully rough turbulent boundary layers," Journal of Fluid Mechanics, Vol. 162, 1986, p. 69-98. doi:10.1017/S0022112086001933.

[19] Grigson, C., "Drag losses of new ships caused by hull finish,” Journal of Ship Research, Vol. 36, No. 2, 1992 , pp. $182-196$.

[20] Aupoix, B., "Roughness corrections for the $k-\omega$ shear stress transport model: status and proposals," Journal of Fluids Engineering, Vol. 137, No. 2, 2015, pp. 1-10. doi:10.1115/1.4028122.

[21] Wilcox, D. C., "Reassessment of the scale-determining equation for advanced turbulence models," AIAA Journal, Vol. 26, No. 11, 1988, pp. 1299-1310. doi:10.2514/3.10041.

[22] Wilcox, D. C., "Formulation of the $k-\omega$ turbulence model revisited," AIAA Journal, Vol. 46, No. 11, 2008, pp. $2823-2838$. doi:10.2514/1.36541.

[23] Hellsten, A., and Laine, S., "Extension of $k-\omega$ shear-stress transport turbulence model for rough-wall flows," AIAA Journal, Vol. 36, No. 9, 1998, pp. 1728-1729. doi:10.2514/2.7543.

[24] Knopp, T., Eisfeld, B., and Calvo, J. B., “A new extension for $k$ - $\omega$ turbulence models to account for wall roughness," International Journal of Heat and Fluid Flow, Vol. 30, No. 1, 2009, pp. 54-65. doi:10.1016/j.ijheatfluidflow.2008.09.009.

[25] Jachimowski, C. J., "An analytical study of the hydrogen-air reaction mechanism with application to scramjet combustion." NASA TP 2791, 1988.

[26] Toro, E. F., Spruce, M., and Speares, W., "Restoration of the contact surface in the HLL-Riemann solver," Shock Waves, Vol. 4, No. 1, 1994, pp. 25-34. doi:10.1007/BF01414629.

[27] Van Leer, B., “Towards the ultimate conservative difference scheme. V. A second-order sequel to Godunov's method,” Journal of Computational Physics, Vol. 32, No. 1, 1979, pp. 101-136. doi:10.1016/0021-9991(79)90145-1.

[28] Van Leer, B., "Towards the ultimate conservative difference scheme. II. Monotonicity and conservation combined in a secondorder scheme.” Journal of Computational Physics, Vol. 14, No. 4, 1974, pp. 361-370. doi:10.1016/0021-9991(74)90019-9.

[29] Ribeiro, F. H. E., Boukharfane, R., and Mura, A., "Highly-resolved large-eddy simulations of combustion stabilization in a scramjet engine model with cavity flameholder," Computers and Fluids, Vol. 197, 2020, p. 104344. doi:10.1016/j.compfluid. 2019.104344 . 